\title{
Ensino de Geología Ambiental no ambiente urbano
}

\section{Teaching of Environmental Geology in the urban environment}

\section{ALVES}

Departamento de Ciências da Terra/Escola de Ciências

LandS/Lab2PT - Laboratório de Paisagens, Património e Território (FCT UID/AUR/04509/2013; FEDER COMPETE POCI-01-0145-FEDER-007528)

Universidade do Minho, Braga, Portugal

E-mail: casaix@dct.uminho.pt

\begin{abstract}
Financial restrictions on higher education have affected diverse study areas and their effects can be considered particularly negative for those subjects that require fieldwork, as is the case of Geology. Under these circumstances, the recourse to local features will be especially valuable. In this work are presented some examples that are potentially interesting for the teaching of Environmental Geology and that concern observations of local geology and built structures. Examples of observations of local geology include outcrops exposed by weathering and erosion as well as expositions resulting from human interventions. The later could allow the study of portions not available otherwise and, potentially, in a 4D (space + time) perspective (this includes the creation of conditions that favour the observation of dynamic situations such as mass movements or groundwater variations). The study of geologic
\end{abstract}


materials and analogues of geological processes in built structures might help to overcome some of the limitations of local geology and can also be considered as relevant geological studies in the context of the Anthropocene.

keywords: Anthropocene, science education, field observations, geological analogues, geologic materials. 


\section{INTRODUÇÃO}

O ensino universitário está submetido a limitações significativas de verbas em diversos países e as mesmas são particularmente penalizantes para o ensino de temas que envolvem deslocações, como é o caso da Geologia, uma vez que, para além das limitações laboratoriais e de pessoal (comuns à generalidade das áreas de estudo), as restrições orçamentais afetam a capacidade de realizar trabalhos de campo ou visitas de estudo. Assim sendo, existe um especial interesse em tentar valorizar os elementos disponíveis nos locais onde estão sediadas as instituições de ensino. Adicionalmente, as atividades letivas no ambiente modificado pelo ser humano vão ao encontro de um dos temas polémicos dos estudos geológicos atuais: a definição de uma unidade crono-estratigráfica relacionada com a atividade humana, sendo o Antropoceno uma das propostas mais comuns, ainda que existam outras (ver discussão em ALVES, 2017).

Podem ser encontrados vários exemplos de estudos do desenvolvimento de organismos e das relações ecológicas no ambiente modificado e criado pelos seres humanos (incluindo livros como SCHILTHUIZEN, 2018, mostrando este tipo de publicação a maturidade do assunto). Essa perspetiva é mais rara no domínio da Geologia. Todavia, várias iniciativas podem ser encontradas em termos de divulgação e ensino, como por exemplo https://education.usgs.gov/lessons/ schoolyard/ e https://serc.carleton.edu/teachearth/index.html (com várias atividades relacionáveis com a Geologia Ambiental). MCKENZIE ET AL. (1978) apresentam uma revisão, tendo em vista atividades le- tivas, de vários estudos anteriores com os principais conceitos envolvidos na Geologia Ambiental em ambiente urbano, focados nas questões geológicas resultantes da interação do ser humano com os terrenos e defendo que a Geologia Ambiental é um tema frequentemente urbano. Curiosamente este artigo não tem qualquer citação no "Google Scholar". A maioria dos artigos encontrados no "Google Scholar" pela pesquisa da expressão "Urban Environmental Geology" corresponde a estudos em regiões asiáticas, refletindo, talvez, o acelerado desenvolvimento urbano nessas regiões.

Neste trabalho não se pretende apresentar uma extensa revisão do tema mas antes discutir alguns exemplos ilustrativos, com base na experiência do autor. A expressão "ambiente urbano" neste trabalho incluirá os terrenos em redor dos agregados populacionais acessíveis em períodos de tempo e custos de transporte compatíveis com a atividade quotidiana. Todas as imagens apresentadas são de locais em Portugal, a maior parte em Braga.

No seguimento de publicações anteriores onde era considerada, entre outros assuntos, a utilização do ambiente urbano para o ensino das Geociências (ALVES, 2017, 2018), pretende-se apresentar neste trabalho exemplos potencialmente ilustrativos da utilização de observações no ambiente urbano para o ensino de conceitos relacionados com a Geologia Ambiental. O corpo do trabalho (entre esta introdução e as considerações finais) compreende duas secções: uma dedicada a superfícies da geologia local, incluindo afloramentos (superfícies naturais) e exposições resultantes da atividade humanas, e outra dedicada a observações de materiais e processos nas estruturas humanas. 
EXPOSIÇÕES DA GEOLOGIA LOCAL

Uma questão inicial a considerar corresponde à delimitação do âmbito daquilo que será considerado o ambiente geológico (processos e produtos). Os seres humanos têm sido referidos como uma "força geológica" (NRC, 1988, refere essa ideia numa publicação de 1945 de V.I. Vernadsky) mas o assunto não é consensual; a International Mineralogical Association (IMA) considera que todos os produtos resultantes da ação humana devem ser excluídos do conceito de mineral (NICKEL 1995). Este tipo de questões também será potencialmente interessante para a discussão em torno da definição do Antropoceno. Tenho discutido o assunto com mais detalhe noutras publicações (ver ALVES 2017), defendendo que as alterações do ambiente humano que não resultam de ação deliberada podem ser incluídas entre os processos geológicos. Todavia, numa perspetiva conservadora, neste artigo as expressões processos, produtos e ambiente geológico, abrangem unicamente o que existiria sem ação humana (deliberada ou não).

Em geral, há pelo menos algumas ocorrências superficiais de corpos geológicos no ambiente urbano, incluindo os seus arredores imediatos, em resultado de processos geológicos ou da ação humana, cuja utilidade para a lecionação de conceitos de Geologia Ambiental será muito variável de acordo com as características geológicas do terreno. $\mathrm{O}$ "Google Maps" permite observar que mesmo em mega urbes como Nova Iorque ou Tóquio há locais de visualização de corpos geológicos, por exemplo nos parques ou junto de margens de rios ou nas zonas costeiras.

As escavações associadas com a atividade antropogénica (abrangendo as escavações para extração de materiais geológicos e matérias-primas minerais, construção de estruturas civis e podendo incluir, também, as escavações arqueológicas) revelam superfícies de observação da geologia regional e dos seus processos (Figura 1). 


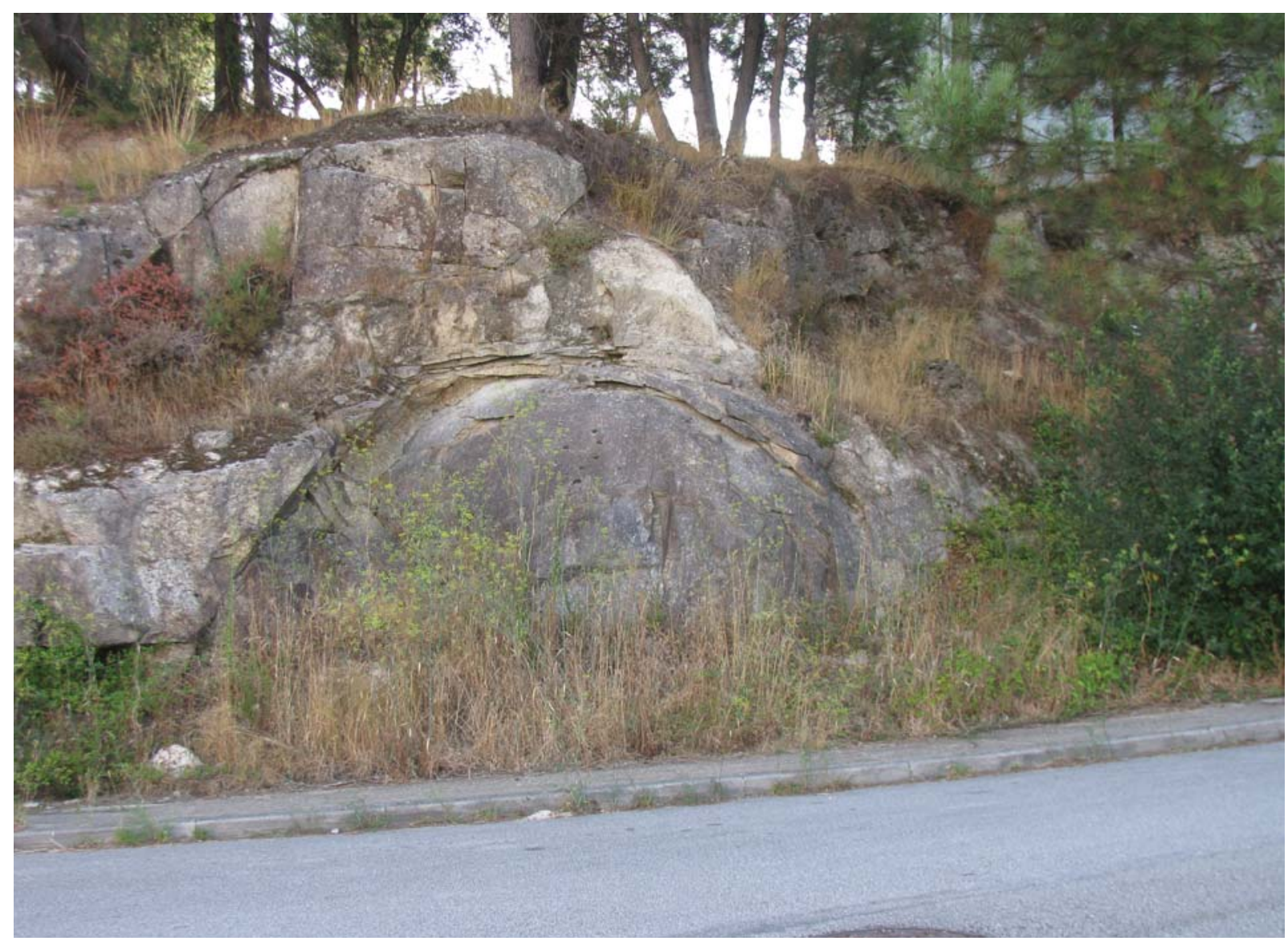

Fig. 1. Corte numa rua de Braga que mostra o início da meteorização em bolas (processo na origem dos caos de blocos).

Podemos incluir, igualmente, os blocos de rochas "exumados" pelas escavações, existindo exemplos de incorporação dos mesmos na paisagem humanizada. Aconselha-se, por isso, aos interessados na área da Geologia, uma perspetiva 4D (espaço + tempo) com particular atenção à realização de obras de construção (que poderão mostrar, por vezes durante um intervalo restrito de tempo, exemplos habitualmente não disponíveis). As escavações associadas com a extração de recursos minerais são ainda úteis para discutir a questão do impacte paisagístico, que deveria incluir o efeito benéfico de expor o substrato geológico (que faz parte da natureza local).
Em condições favoráveis é possível observar a evolução lateral e com a profundidade das características do terreno, nomeadamente em termos de perfil de meteorização (Figura 1b), por vezes ao longo do tempo, assim como as implicações dessa evolução em termos dos seus impactes e perigosidade para as pessoas envolvidas na escavação, da poluição associada (e.g., a poluição sonora), as implicações em termos de consumo de recursos e sustentabilidade, assim como das intervenções necessárias para manter a estabilidade da mesma.

Alguns dos exemplos porventura mais comuns que podem ser encontrados nestas exposições em ambiente urbano relacionam-se com fraturação e meteorização. 
Os aspetos de fraturação e meteorização permitem discutir questões relacionadas com os movimentos de massas (em vertentes e taludes). Assim, estes processos deixam blocos de rocha soltos com risco de movimentação ou cortes com blocos de rocha dura no meio de rocha muito alterada (tipo solo) que por erosão poderão libertar-se (Figura 1).

A preservação de descontinuidades estruturais em maciços muito alterados (Figura 2) será também relevante para estas questões uma vez que perturbam a aplicação de

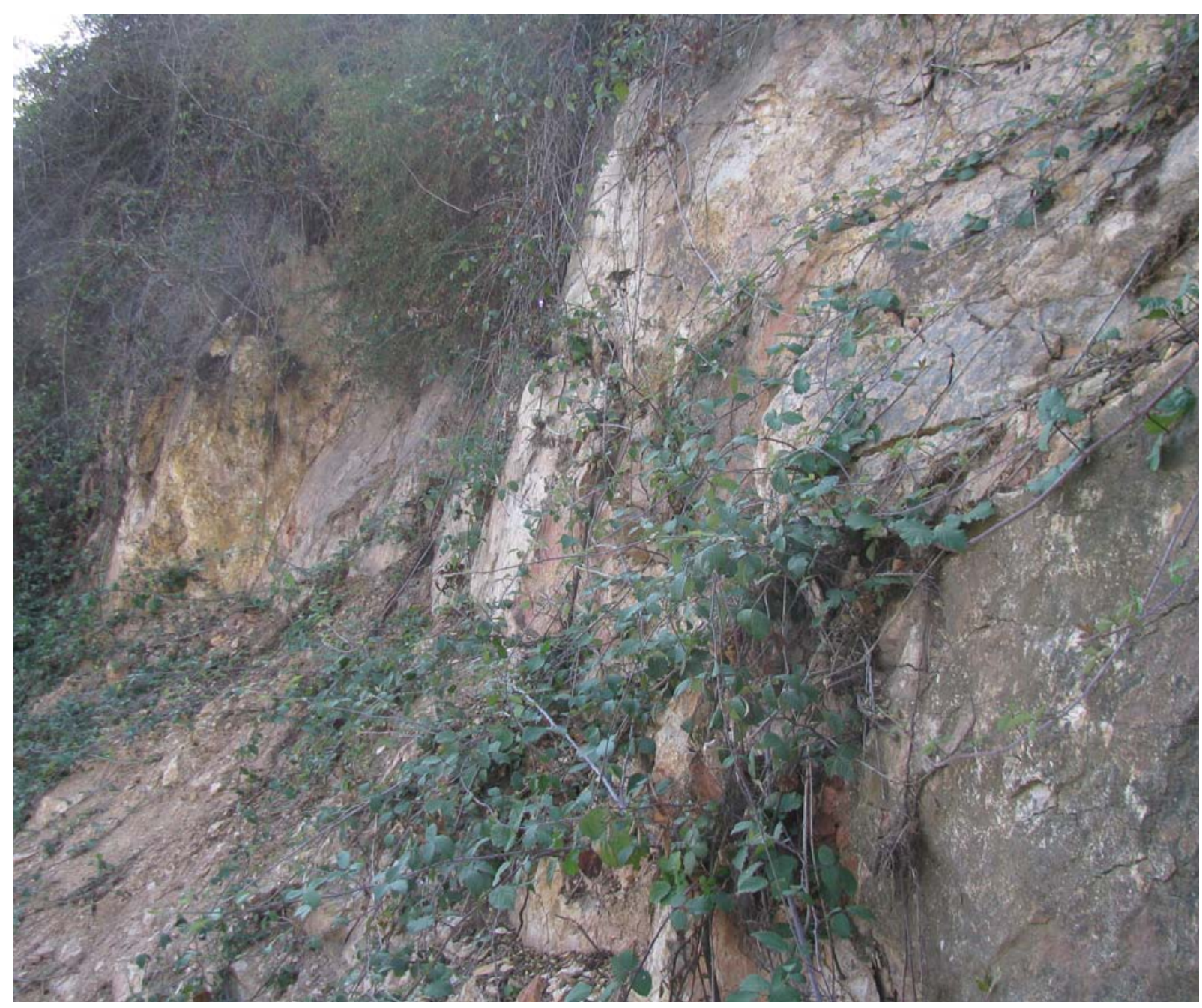

Fig. 2. Maciços muito alterados com descontinuidades que podem afetar o comportamento dos mesmos em termos de movimentos de massas (notar também a relação entre as descontinuidades e as raízes de árvores).

modelos de corpos de solos homogéneos e isotrópicos, muito populares em estudos de Engenharia Civil.

A frequência e orientações das fraturas podem, também, criar situações de instabilidade em taludes e vertentes por desmoro- namento ou por movimento ao longo dos planos de descontinuidades ou das intersecções destes, nomeadamente em função das relações direcionais das estruturas e das superfícies de exposição. As intervenções humanas têm, portanto, o potencial de criar 
novas situações favoráveis aos movimentos de massa, por exemplo, ao criar taludes com características geométricas (tamanho e orientação) favoráveis aos mesmos.
Esta questão da instabilidade é sublinhada pelas medidas de intervenção para estabilidade (Figura 3) e do ponto de vista da Geologia Ambiental também existirá in-

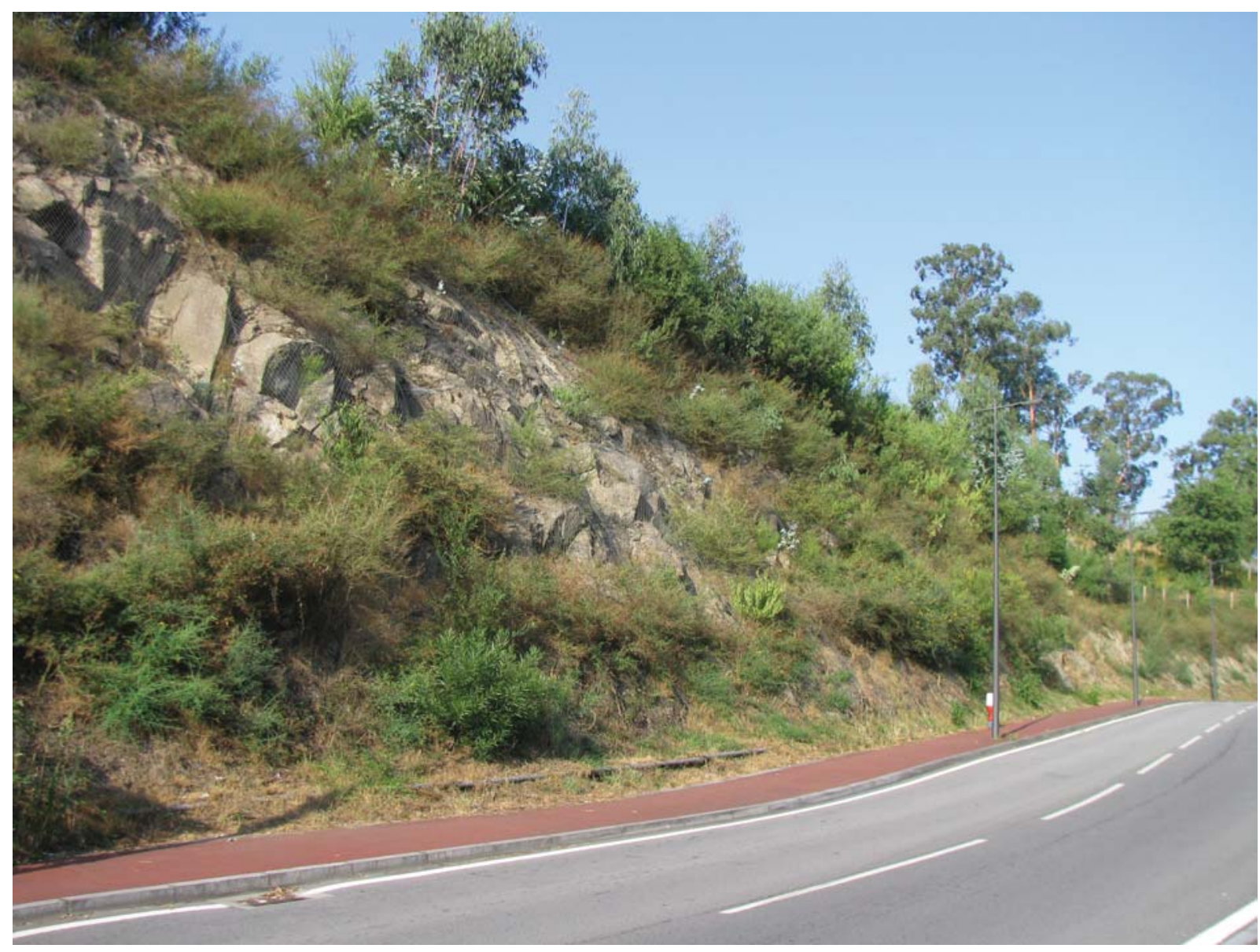

Fig. 3. Redes de contenção para estabilização de talude. Reparar ainda no extenso desenvolvimento da vegetação neste talude com menos de uma década de exposição.

teresse em observar as soluções para estes problemas relacionados com as características geológicas do terreno.

Em alguns taludes é visível o rápido desenvolvimento da vegetação, ilustrando relações entre o desenvolvimento biológico e o substrato, assim como a recuperação natural de locais com intervenção humana (conceitos que poderão ser estendidas a outras questões como a recuperação de áreas com antigas explorações de recursos minerais).
A fraturação e meteorização servem para discutir questões relacionadas com recursos hídricos subterrâneos como a área de recarga, assim como a circulação de águas e dos poluentes que as podem afetar.

As variações litológicas e do estado de alteração podem ser relacionadas com os impactes dos sismos, dados os efeitos que as mesmas podem ter na amplificação das ondas sísmicas (Price \& De Freitas, 2009). Adicionalmente, as porções meteorizadas 
podem ser utilizadas para a discussão de processos que promovem o consumo de $\mathrm{CO}_{2}$. A presença de ocorrências visíveis de argilas, para além de, como referido, ser relacionável com os movimentos de massa e com a fixação de $\mathrm{CO}_{2}$, permite discutir a utilidade destes materiais em domínios ambientais (revestimento de aterros, filtros de poluentes e até, alargando o âmbito até a Geologia Média, a preparação de medicamentos).

Numa espécie de ponte para a secção seguinte, as exposições dos corpos geológicos podem ser discutidos enquanto potenciais locais do desenvolvimento de estruturas humanas com interesse ambiental. Uma das situações mais comuns em termos de estruturas ambientais corresponde à construção de depósitos de resíduos (as características necessárias estarão relacionadas com o tipo de resíduo) mas as características dos terrenos são relevantes para outras estruturas como as barragens ou os parques eólicos. Um ponto talvez ainda mais interessante será a utilização dos corpos geológicos como locais de alojamento de seres humanos (em cavernas naturais ou resultantes de escavação), situação que vindo do passado, continua ser observada no presente e poderá continuar no futuro, tendo em consideração as potencialidades em termos de conforto climático (um aspeto eventualmente exacerbado pelo aquecimento global).

Mas muitos outros exemplos de diversos aspetos poderão ser encontrados em função da geologia regional, como é o caso das rochas vulcânicas (nomeadamente as piroclásticas), ou a relação das rochas calcárias com a retenção de $\mathrm{CO}_{2}$, ou a evidência de movimento em falhas que atravessam formações recentes e que são elementos de estudo da paleossismicidade. Existem situações em que é possível observar exsurgências de água subterrânea em associação com as formações geológicas, abrindo assim linhas de discussão sobre esta importante vertente ambiental (incluindo questões relacionadas com a caracterização físico-química das águas e com a avaliação de caudal e a relação do mesmo com as variações temporais da meteorologia). O número de possibilidades com interesse letivo é enorme e não será explorada aqui. Claro que a dimensão restrita das exposições disponíveis será com frequência uma marcada limitação ao estudo de estruturas tectónicas. Mas em áreas com cartografia geológica disponível, existe a possibilidade de procurar evidências relacionáveis com as estruturas representadas na mesma (atualmente será fácil fazer isso com os smartphones).

Por outro lado, os assuntos que podem ser estudados em afloramentos ou escavações numa determinada região estão limitados às características da geologia regional. Esse tipo de restrição pode ser ultrapassado, pelo menos em parte, pelo estudo das estruturas humanas.

\section{ESTRUTURAS HUMANAS}

A expressão "estruturas humanas" será utilizada aqui com um sentido muito alargado, incluindo paisagens, esculturas, etc.

A potencial utilidade das estruturas humanas para a discussão letiva de conceitos de geologia ambiental pode começar pela consideração de impactes da própria estrutura, com base em alguns pontos da discussão do ponto anterior, como por exemplo a perturbação da área de recarga de recursos hídricos subterrâneos. As estruturas são geralmente construídas com materiais extraídos e processados mas observam-se 
exemplos onde os corpos geológicos são integrados nas estruturas, permitindo a preservação das ocorrências "in situ" dos mesmos, assim como de situações que ilustram a importância destes, por exemplo enquanto locais de ocorrência de emergência de águas (Figura 4), promovendo, como referido na secção anterior a discussão de assuntos rela-

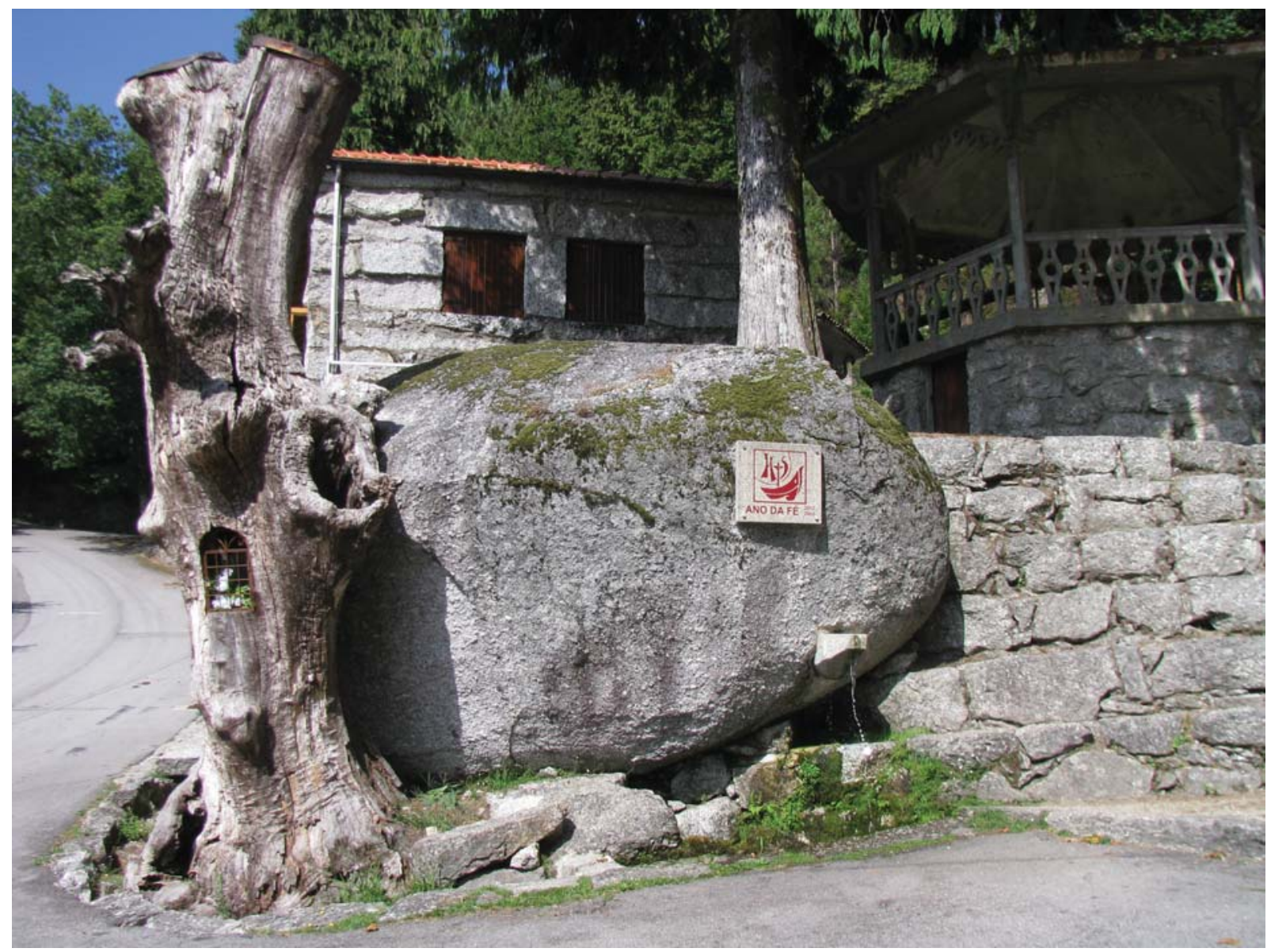

Fig. 4. Incorporação no ambiente construído de bloco granítico com nascente de água.

cionados com as águas subterrâneas (outro exemplo particularmente interessante é a Fonte do Ídolo, situada em pleno centro da cidade de Braga - ver https://www.cm-braga. $\mathrm{pt} / \mathrm{pt} / 1201 /$ conhecer/historia-e-patrimonio/ museus/item/item-1-669). Incluem-se nestes exemplos a preservação de blocos da geologia local na paisagem pós-intervenção humana.

As estruturas humanas podem ainda ter interesse em termos de registo de evidências de processos geológicos (e, obviamente, também dos seus análogos que serão descritos mais adiante). Em relação à atividade sísmica, podem ser encontrados exemplos de fraturas associadas com eventos sísmicos e as características da construção das estruturas podem relacionar-se com a perigosidade sísmica da região onde as estruturas estão localizadas. Estas observações são uma potencial fonte de informação em termos de sismicidade histórica. Um outro exemplo de utilização de estruturas humanas enquanto registo é encontrado em LYELL (1854), 
que utiliza observações do Templo de Serapis em Pozzuoli (Itália) como evidências de variações significativas do nível das águas do mar. Em alguns exemplos é possível ver a relação entre as estruturas e as fundações no substrato geológico e os efeitos da instabilidade nesse substrato para as estruturas (Figura 5).

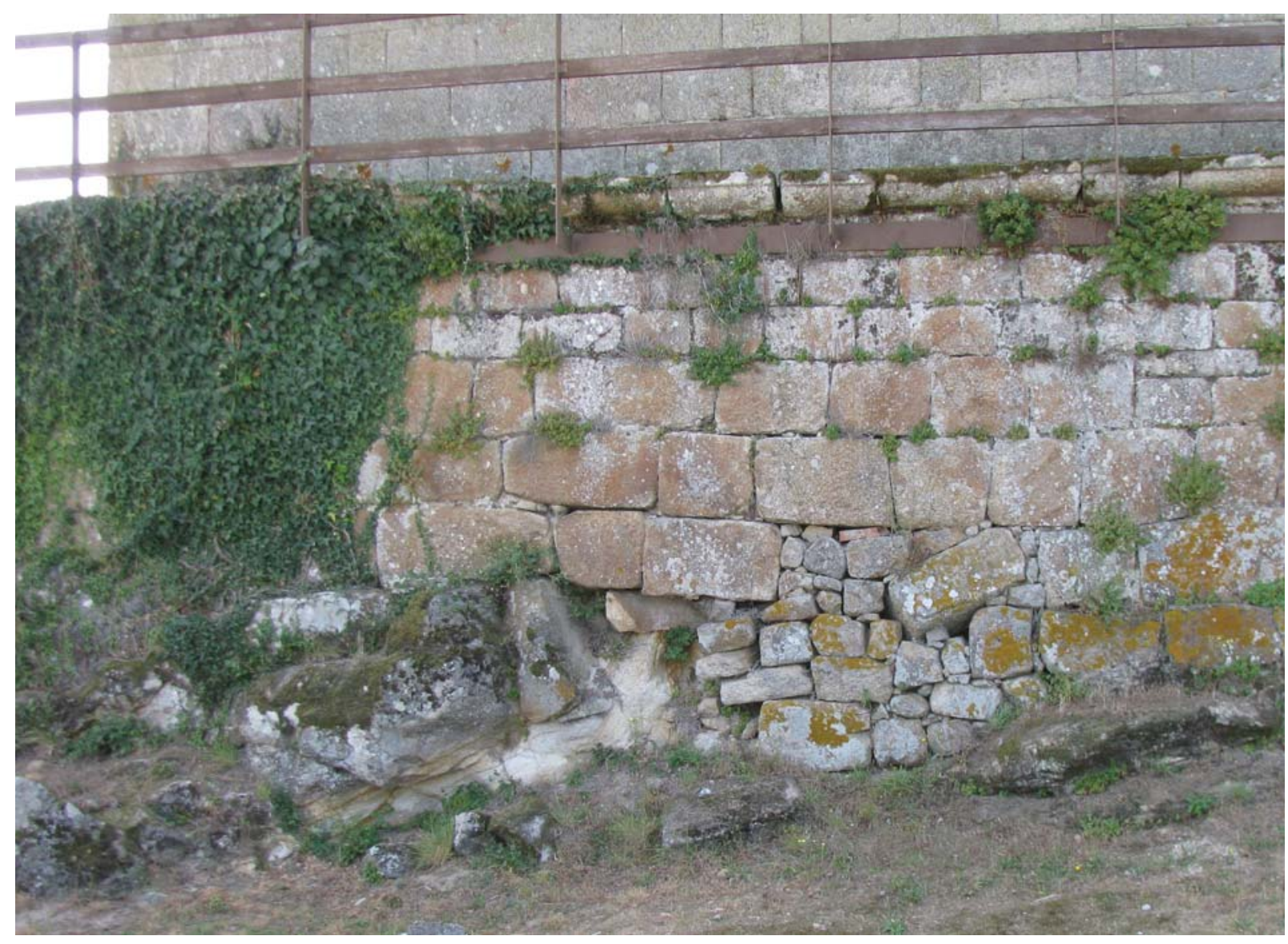

Fig. 5. Efeito em estrutura humana da instabilidade no maciço rochoso na base da estrutura.

No contexto deste trabalho, a designação "materiais geológicos" será utilizada para diversas aplicações de rochas (blocos, placas e agregados). Os materiais geológicos usados nas estruturas podem ser relacionados com processos com impacte ambiental, tal como os exemplos referidos na secção anterior em relação às litologias. Por exemplo, a presença de granitos com contrastes macroscópicos de grau de meteorização (Figura 6a) pode ser utilizada para discutir a relação destes processos com $\mathrm{O} \mathrm{CO}_{2}$. O estado de meteo- rização serve ainda para discutir assuntos relacionados com a sustentabilidade; materiais mais meteorizados são mais fáceis de trabalhar, consumindo menos recursos, mas podem corresponder a uma maior quantidade de resíduos (que poderá ser minimizada pela via da reciclagem) e se os materiais forem menos duráveis existirá um risco de aumento de consumos associados com a sua manutenção.

As estruturas humanas que incluem materiais geológicos não locais, aquilo que 


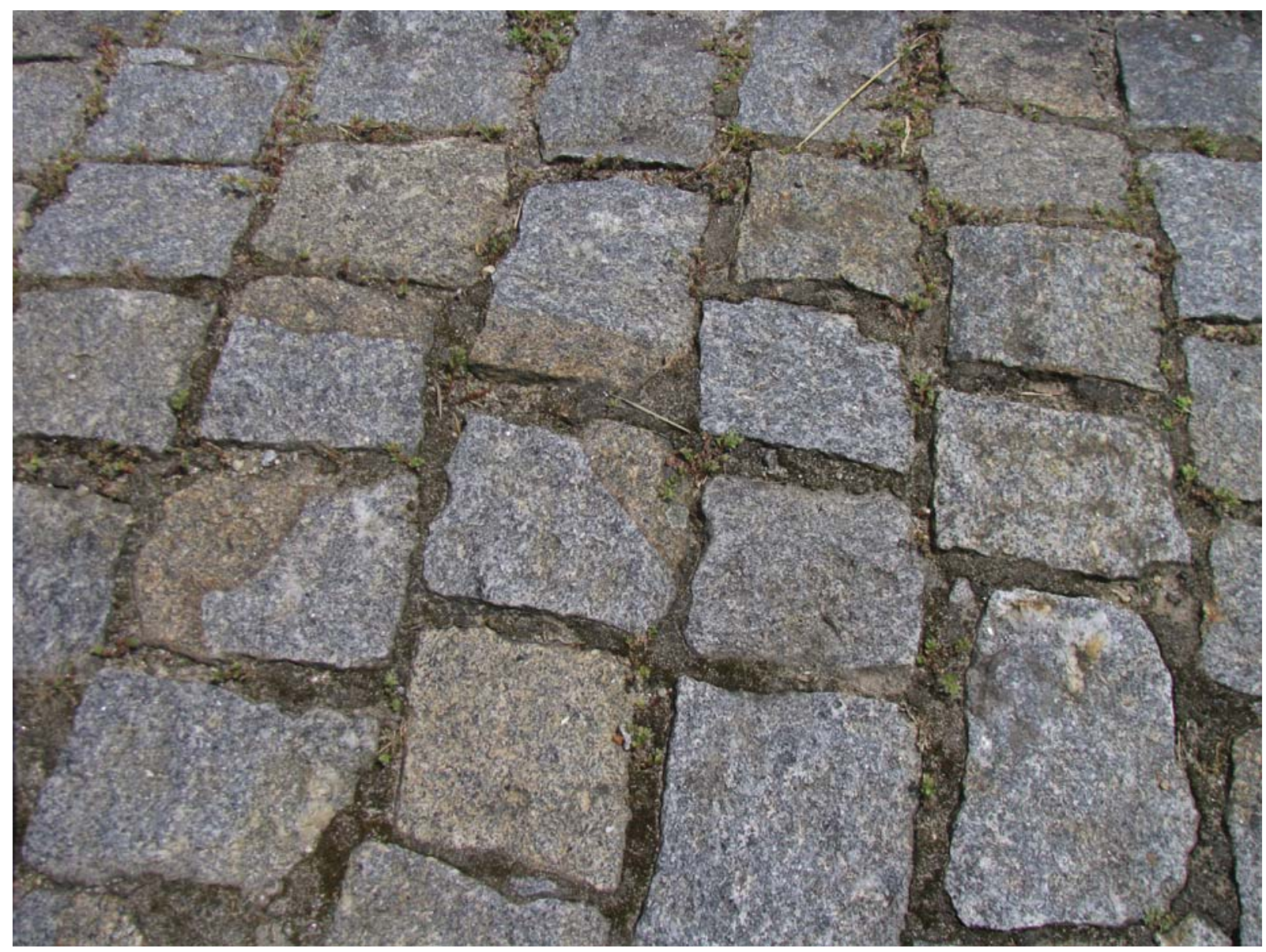

Fig. 6. Blocos de granito ilustrativos de processos geológicos: a) pedras com diferentes graus de meteorização (marcada pelo contraste cromático amarelo/cinzento).

HAZEN ET Al. (2017) designam por xenólitos antropogénicos, criam condições para ultrapassar as limitações da geologia no local. Claro que existe um problema de escala que em geral inibe a discussão de temas relacionados com as estruturas geológicas. Mas a presença de pedras com faces que correspondem a planos de diaclases (Figura 6b) permite discutir questões associadas com os efeitos da presença das mesmas (como as referidas na secção anterior).

Mas será ainda possível relacionar as características dos materiais com os impactes da extração dos mesmos, nomeadamente pela comparação de diversas opções de materiais (por exemplo diferentes tipos de 


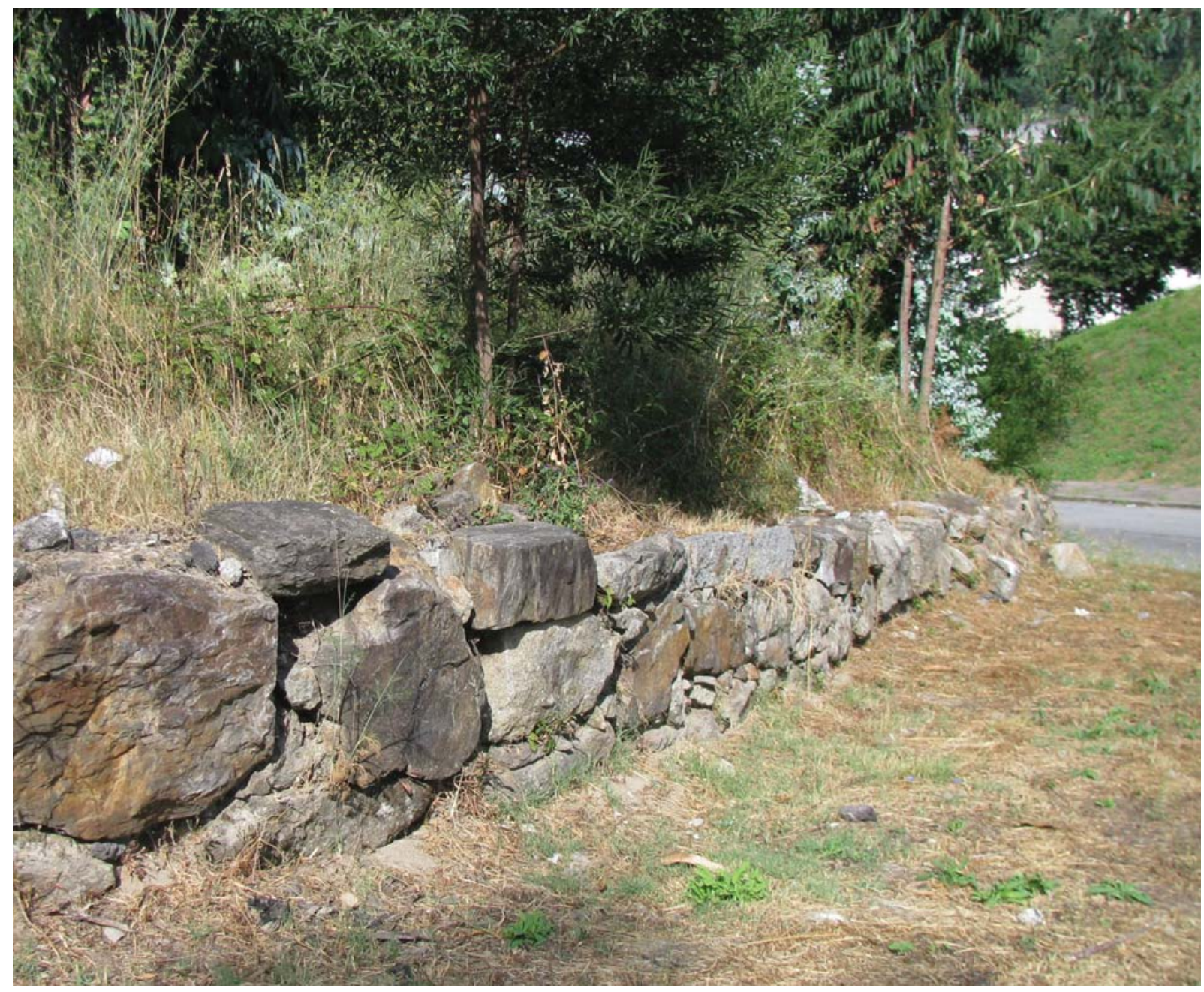

Fig. 6. Blocos de granito ilustrativos de processos geológicos. b) blocos com evidências de paredes de diaclases.

produtos como agregados, placas ou blocos de pedra), assim como a relevância de características estruturais nesses impactes, como seja a influência de anisotropias penetrativas (xistosidade, etc.) na facilidade de obtenção de peças, com menor consumo de energia e outros recursos.

Será também interessante considerar misturas destes materiais geológicos e de outras substâncias (especialmente no caso dos agregados em que possível introduzir a discussão dos ligantes de cimento ou betuminosos). A presença destes ligantes pode relacionar-se também com conceitos geológicos como os hidrocarbonetos ou, no caso dos ligantes de cimento e cal, com a utilização de calcários (permitindo exercícios quantitativos simples em termos de produção de $\mathrm{CO}_{2}$, com revisão de conceitos mineralógicos de base mas com relevância ambiental). Alguns destes materiais incorporam partículas de corpos sedimentares que servem para referir os problemas ambientais específicos associados com a exploração destes em relação com a erosão fluvial e costeira. Materiais com resíduos de pedreiras promovem a discussão da valorização desses mesmos resíduos (ilustrando como as preocupações 
ambientais podem ser uma fonte de receita pela via da inovação).

A observação de construções históricas, nomeadamente vernáculas, permite discutir (ver SANJURJO-SÁNCHEZ \& ALVES, 2017) as vantagens ambientais de antigas práticas construtivas, como a arquitetura de terra e mesmo o uso de pavimentos em pedra (por comparação com outros materiais). As construções em terra, nomeadamente, estão a experimentar uma certa revalorização pelo seu menor impacte ambiental e por aspetos relacionados com a comodidade termal, encontrando-se já publicações de divulgação popular para as mesmas, até para o mundo ocidental (e.g. HUNTER \& KIFFMEYER, 2004), que promovem diversos materiais de acordo com a utilização prevista. Outra característica de materiais geológicos que pode ser valorizada é a cor, com as cores muito claras associadas com os "cool materials" (ver SANJURJO-SÁNCHEZ \& ALVES, 2017).

Adicionalmente, os materiais geológicos são utilizados em algumas intervenções de interesse ambiental como o revestimento argiloso de aterros de resíduos ou os agregados utilizados para a estabilização de taludes.

A discussão do uso dos materiais permite, portanto, relacionar estes estudos com outras áreas de estudo, nomeadamente arquitetura e engenharia, potencialmente com interesse do ponto de vista profissional para os alunos.

Os materiais geológicos utilizados nas estruturas humanas podem ser também discutidos enquanto fontes de poluentes e isso pode ser evidenciado por alguns dos exemplos que iremos discutir seguidamente (a questão da poluição será vista aqui de uma forma muito alargada, incluindo os poten- ciais efeitos sobre outros materiais presentes nas estruturas).

As maiores limitações do estudo das estruturas humanas, em termos de ensino de Geologia Ambiental, podem estar associadas com o ensino da sismicidade em áreas com fraca atividade sísmica (ausência de evidências) e com o vulcanismo piroclástico, dado o limitado uso destas rochas fora das regiões de ocorrência.

As estruturas humanas oferecem também oportunidades de observar processos análogos de processos geológicos com relevância ambiental, assim como dos produtos dos mesmos, incluindo processos não ocorrentes no contexto geológico local. Em condições favoráveis, as observações das estruturas humanas podem ainda servir para observar o desenvolvimento dos processos ao longo do tempo.

Um exemplo de utilização de observações de processos antropogénicos como análogos para a apresentação de processos geológicos é apresentado em LYELL (1854), que utiliza observações de precipitados que ocorrem em caldeiras de vapor como explicação de algumas características texturais de calcários.

Os processos análogos com interesse ambiental mais comuns no ambiente construído correspondem a relações entre organismo e substratos, observáveis na generalidade das superfícies exteriores e em algumas interiores. Um exemplo que é frequentemente encontrada corresponde à associação entre a tipologia de organismo e as condições de humidade do substrato, com as ocorrências de musgos limitadas a zonas de humidade mais perene enquanto biofilmes de algas, fungos e líquenes podem ser encontrados em locais de humidade mais intermitente. Uma diferenciação de organismos pode ser tam- 
bém observada em relação às características do substrato em termos das características dos espaços vazios: algas, fungos e líquenes em substratos pouco porosos (ainda que no caso dos líquenes seja necessário pelo menos alguma irregularidade superficial), musgos a preferirem substratos mais porosos e a ocorrência de plantas superiores limitada a macroespaços (incluindo fraturas). Em algumas situações o desenvolvimento das raízes das árvores pode provocar fraturas em pavimentos (constituindo ilustrações de processos geomorfológicos).
Este tipo de observação pode relacionarse com outras áreas de estudo no contexto naturalista-urbano, nomeadamente dos estudos ecológicos no ambiente antropogénico, ponto de vista que será interessante para formações com uma componente ambiental mais forte. Numa perspetiva muito alargada de Geologia Ambiental, as observações das relações entre organismos e substratos permitem referir questões relacionadas com a panspermia e a origem da vida.

Algumas situações do ambiente construído (Figura 7) mostram a recuperação da

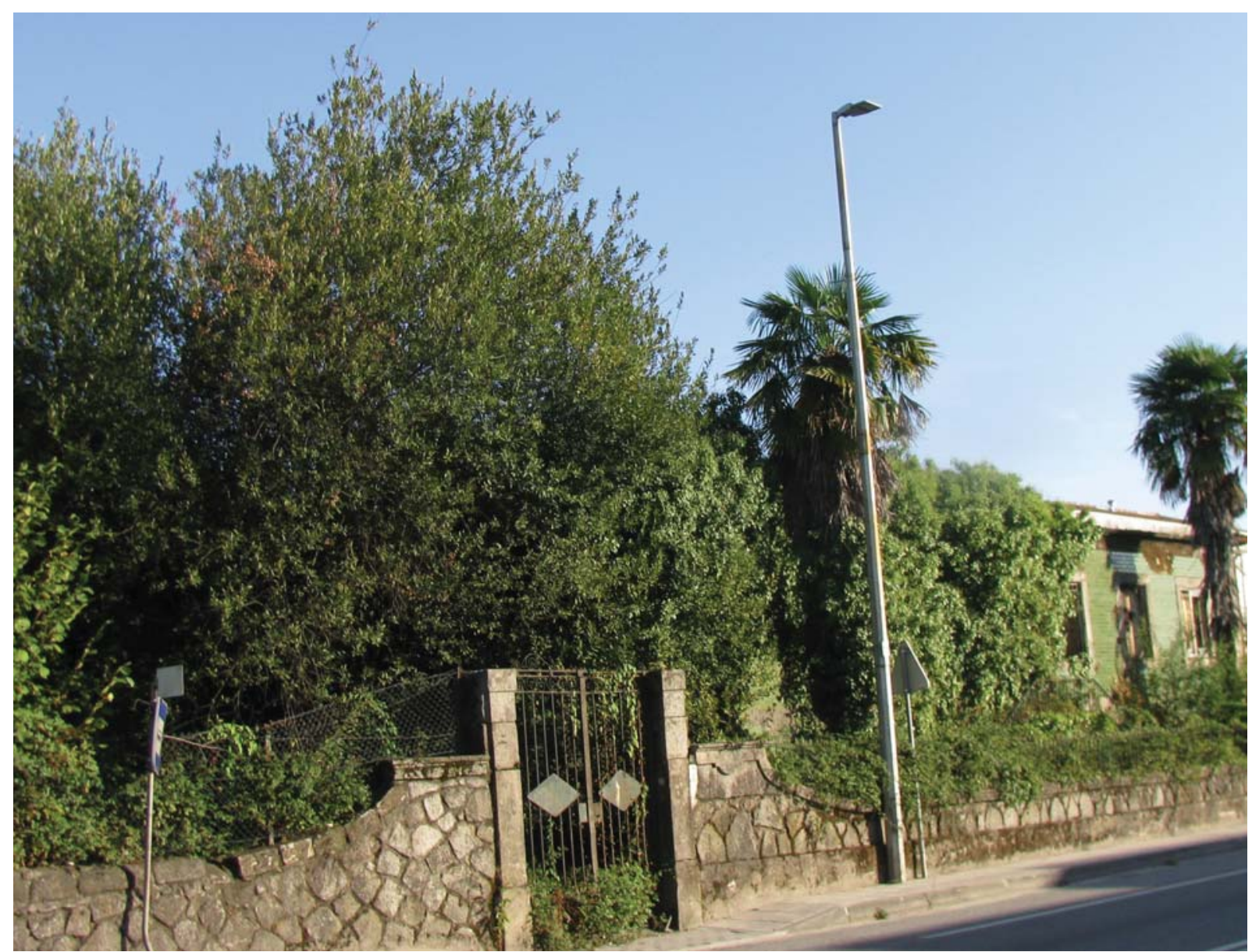

Fig. 7. Exemplo de estrutura abandonada com intenso avanço da vegetação.

vegetação com o quase desaparecimento das estruturas construídas, ilustrando a possibili- dade de recuperação ambiental de escavações (como as observadas na secção anterior). 
A interação dos materiais geológicos (e outros materiais) presentes nas estruturas com diversos agentes promove a ocorrência de produtos com interesse para o ensino da Geologia Ambiental.

Encontram-se casos de alteração dos elementos constituintes dos materiais geológicos, como as manchas resultantes da alteração de sulfuretos (ver ALVES, 2017, 2018), processo ilustrativo de um dos problemas que interessa os estudos de Geologia Ambiental: a geração de águas ácidas em associação com a alteração de escombreiras de explorações de sulfuretos.
A presença de efeitos erosivos é algo frequente no património histórico mas relativamente infrequente nas construções humanas mais recentes. Na larga maioria das situações, os efeitos erosivos estão associados com a presença de contaminação salina, sendo por isso algo limitadas em termos de representatividade geológica. Todavia, estes processos erosivos geralmente definem padrões espaciais relacionáveis com a migração de poluentes (Figura 8), servindo na discussão da pesquisa de fontes de poluição. A recorrência de efeitos erosivos também tem interesse em termos de discussão do

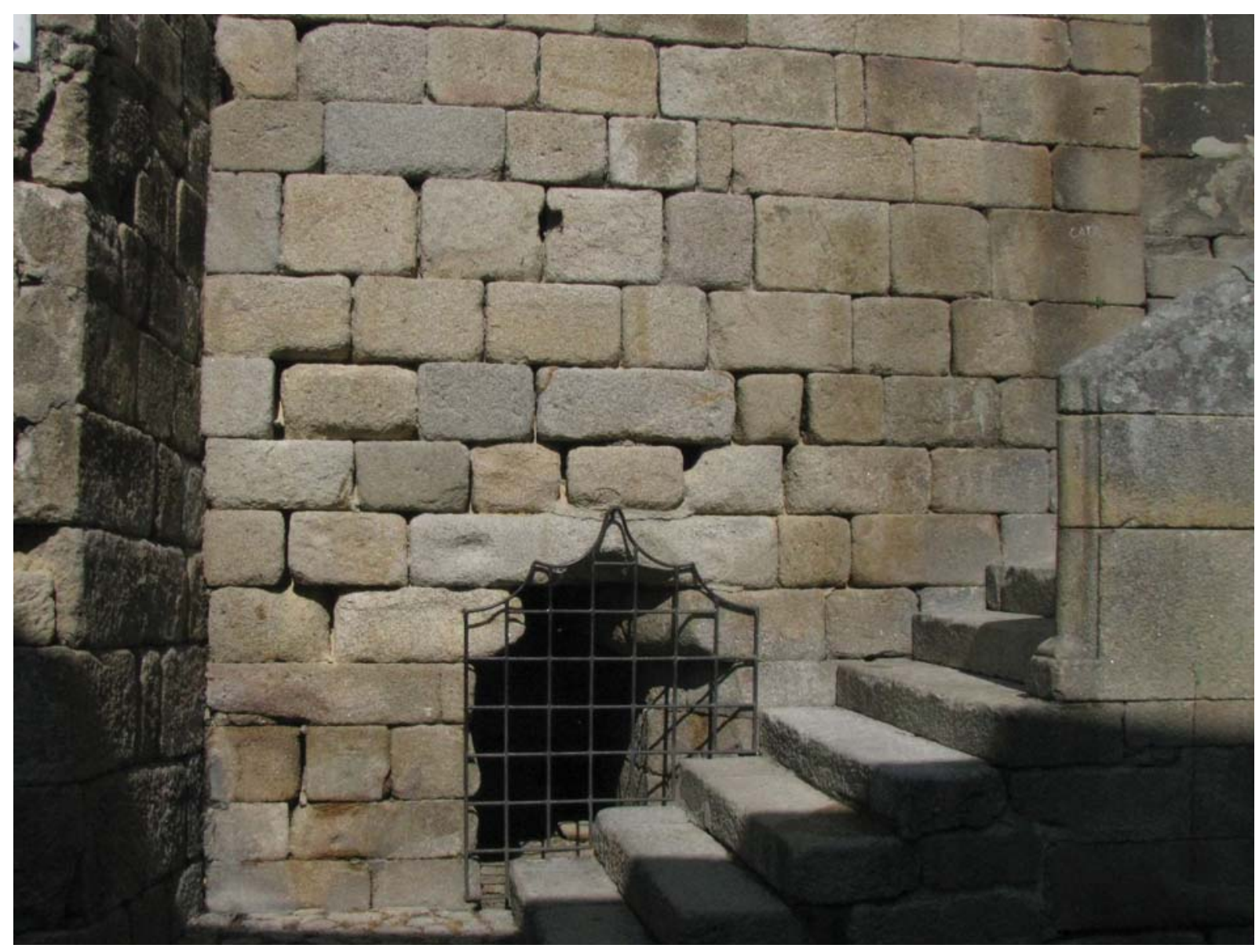

Fig. 8. Padrões de erosão em parede sugestivos da migração da poluição salina (a erosão dos blocos diminui com a altura e é mais acentuada ao longo dos limites entre estes). 
comportamento de focos de poluição. Adicionalmente, estes processos têm uma visibilidade que ajuda a transmitir os conceitos envolvidos.

Ainda neste contexto refira-se a ocorrência de fraturas que servem para ilustrar o comportamento frágil dos corpos geológicos (essencial para a discussão da origem dos sismos) e a contribuição das mesmas para a ocorrência de movimentos de massa (em alguns casos será possível ver a perda de porções dos materiais em associação com as fraturas).

A ação dos diferentes fluidos nas estruturas humanas promove com alguma frequência a ocorrência de neoformações cristalinas com uma diversidade química que será pertinente discutir no contexto ambiental. As fontes das substâncias para estas neoformações cristalinas no ambiente construído são muito diversas, incluindo águas subterrâneas e do solo, atividades humanas do passado e do presente e os próprios materiais de construção (sobretudo os ligantes de cimento ainda que alguns materiais geológicos também são uma potencial fonte de poluentes).

As neoformações cristalinas que ocorrem no ambiente construído podem mostrar fases análogas de minerais que não ocorrem no contexto geológico local e que são globalmente raras (ver ALVES, 2017, 2018). Um exemplo particularmente interessante é o dos nitratos que têm uma distribuição global relativamente restrita no ambiente geológico mas que têm uma ocorrência muito generalizada em construções históricas (ARNOLD \& ZEHNDER 1991; ALVES, 2017).

De entre as diversas neoformações cristalinas ocorrentes nas estruturas construídas consideram-se aqui com mais atenção os precipitados de carbonato de cálcio, dominantes (entre as neoformações) nas construções modernas e que podem também ser encontrados em construções históricas. Alguns destes precipitados resultam da alteração de materiais geológicos com carbonatos mas a generalidade das ocorrências destes produtos está relacionada com a presença de argamassas com cimento, cuja interação com água dá origem a soluções ricas em $\mathrm{OH}^{-}$. A formação dos precipitados carbonatados ilustra a presença do $\mathrm{CO}_{2}$ na atmosfera assim como o princípio do sequestro de $\mathrm{CO}_{2}$ (e uma das potenciais técnicas a usar para esse fim). As neoformações carbonatadas podem ser comparadas com travertinos utilizados no ambiente construído (permitindo a referência a sumidouros geogénicos de $\mathrm{CO}_{2}$ ). Em algumas situações observa-se a recorrência da formação de precipitados carbonatados, salientando a persistência ao longo do tempo das fontes de poluição (ALVES \& SANJURJO-SÁNCHEZ, 2015).

Certas neoformações são ainda um registo de questões de interesse ambiental, como é o caso das chamadas crostas negras, neoformações de gesso com partículas carbonosas e que constituem evidências da poluição atmosférica.

Estes diversos produtos (colonização biológica, neoformações cristalinas, manchas de alteração, efeitos erosivos e fraturas) são visualmente expressivos dos processos de poluição. Adicionalmente muitos deles estão relacionados com a migração de fluidos.

Se considerarmos para a Geologia Ambiental um âmbito alargado que inclui as obras do ser humano, estes processos análogos também serão interessantes pelas suas implicações negativas nessas obras, nomea- 
damente pelas implicações ambientais das operações de conservação e restauro. Claro que se for adotado o ponto de vista de considerar estes processos, que não são controlados pela inteligência humana, como processos geológicos, a evolução das estruturas humanas será um tema de interesse básico para a Geologia Ambiental.

\section{CONSIDERAÇÕES FINAIS}

Nos parágrafos anteriores foram apresentados diversos exemplos ilustrativos das potencialidades do ambiente urbano para o ensino de Geologia Ambiental.

Se bem que os afloramentos de formações geológicas expostos por processos de meteorização e erosão podem ser considerados exemplos mais "naturais" e mais "puros" do ponto de vista geológico, as situações associadas com o ambiente modificado pelo ser humano oferecem, geralmente, informações complementares (raramente encontradas nesses afloramentos cuja exposição não resulta da ação do ser humano), nomeadamente em termos de ensino de Geologia Ambiental.

As escavações humanas permitem obter novas exposições da geologia local, em extensões (lateral e vertical) que podem não estar disponíveis na ausência dessas escavações, aumentando assim a probabilidade de observação de estruturas e litologias (nomeadamente das formações mais suscetíveis aos processos de meteorização e erosão), assim como das variações destas.

Adicionalmente, a ação humana aumenta as condições favoráveis para um estudo 4D do ambiente geológico, incluindo a possibilidade da observação de ocorrências de eventos como os movimentos de massa ou de variações de parâmetros relacionados com as águas subterrâneas (e a relação das mesmas com diversos fatores ambientais).

As estruturas criadas pelo ser humano, para além de permitirem observações da relação entre estas e o ambiente geológico, podem apresentar materiais geológicos e análogos de processos geológicos que não estão disponíveis no contexto local, contribuindo assim para ultrapassar as potenciais limitações pedagógicas desse contexto.

Apesar de o assunto ser potencialmente polémico, o estudo da evolução não projetada das estruturas humanas poderá ser um ponto de interesse válido para os estudos do domínio da Geologia (e para a formação profissional de estudantes desta área), nomeadamente no contexto dos estudos do Antropoceno.

\section{AGRADECIMENTOS}

Este trabalho teve em consideração as atividades letivas do autor no Departamento de Ciências da Terra da Escola de Ciências da Universidade do Minho e as atividades do Lab2PT- Laboratório de Paisagens, Património e Território (também da Universidade do Minho) financiado pela Fundação da Ciência e da Tecnologia (UID/ AUR/04509/2013) através de fundos nacionais e quando aplicável do cofinanciamento do FEDER, no âmbito dos novos acordos de parceria PT2020 e COMPETE 2020 POCI-01-0145-FEDER-007528.

\section{REFERÊNCIAS}

ALVES, C. (2017). Geoscience of the Built Environment: A Contribution for the Perspectives on the Anthropocene. In Horizons in Earth Science Research, Volume 17, Veress, B. Szigethy, J. (Eds.). 
Hauppauge, EUA: Nova Science Publishers, Inc. 978-1-53612-831-4.

ALVES, C. (2018) In Defense of Stamp Collecting: The Importance of Case Studies for Geology Teaching. Proceedings 2018, 2, 563, doi:10.3390/IECG_2018-05340.

ALVES, C., \& SANJURJO-SÁNCHEZ, J. (2015). Conservation of stony materials in the built environment. Environmental Chemistry Letters, 13(4), 413-430. https://doi.org/10.1007/s10311-015-0526-2

ARNOLD, A., \& ZEHNDER, K. (1991) Monitoring wall paintings affected by soluble salts. The Conservation of wall paintings, Cather, S., Courtauld Institute of Art, Getty Conservation Institute, Eds., Getty Conservation Institute: Marina del Rey,EUA 1991, p. 103-135.

LYELL, C. (1854). Principles of Geology or, the Modern Changes of the Earth and Its Inhabitants Considered as Illustrative of Geology, 9th ed., Nova Iorque York, EUA: D. Appleton \& Company

HAZEN, R. M., GREW, E. S., ORIGLIERI, M. J., \& DOWNS, R. T. (2017). On the mineralogy of the "Anthropocene Epoch." American Mineralogist, 102(3), 595-611. https://doi.org/10.2138/am 2017 5875.

HUNTER, K., \& KIFFMEYER, D. (2004). Earthbag building: The tools, tricks and techniques. Gabriola Island,
B.C.: New Society Publishers. 978-155092-303-2

MCKENZIE, G. D., UTGARD, R. O., FOLEY, D., \& MCKENZIE, D. I. (1978). The Essence of Urban Environmental Geology. Journal of Geological Education, 26(1), 32-37, DOI: 10.5408/0022-1368-26.1.32

NRC - NATIONAL RESEARCH COUNCIL (1988). Toward an Understanding of Global Change: Initial Priorities for U.S. Contributions to the International Geosphere - Biosphere Program. Washington, DC: The National Academies Press. ISBN: 978-0-309-07821-4. https:// doi.org/10.17226/1393

NICKEL, E. H. (1995). The definition of a mineral. The Canadian Mineralogist, 33(3), 689-690.

PRICE, D. G., \& DE FREITAS, M. H. (2009). Engineering geology: principles and practice. Berlim Heidelberg, Alemanha. ISBN: 978-3-540-29249-4.

SANJURJO-SÁNCHEZ, J \& ALVES, C. (2017). Sustainability of Stone Materials in The Built Environment of Rural Regions: A Review. Cad. Lab. Xeol. Laxe, v. 39, pp. 141-164.

SCHILTHUIZEN, M. (2018). Darwin comes to town: How the Urban Jungle Drives Evolution. HachetteRU, ISBN 1786481073. 